\title{
A critical comparison of systems management and project management
}

\author{
H. Kerzner \\ Baldwin.Wallace College, Ohio \\ V. Ghyoot \\ Department of Business Economics, University of South Africa, Pretoria
}

\begin{abstract}
Both systems management and project management are discussed in depth, after which the similarities and differences between the two concepts are listed.

S. Afr. J. Bus. Mgmt. 1984, 15: 80-84
\end{abstract}

Beide stelselbestuur en projekbestuur word in diepte bespreek, waarna die ooreenkomste en verskille tussen die twee begrippe gelys word.

S.-Afr. Tyoskr. Bedryfsl. 1984, 15: 80-84

\section{H. Kerzuer}

Business Administration, Baldwin-Wallace College, Ohio

V. Ghyoot*

Department of Business Economics, University of South Africa,

P.O. Box 392, Pretoria 0001, Republic of South Africa

\section{Introduction}

During the past several years, there have been numerous papers published on both project management and systems management, with the words used interchangeably. The systems approach, viewed by many as a way of thinking, is much more than a concept. It is a method or technique of analysis and a managerial style which is operationalized. The strength of the systems approach lies in its view to planning and implementing activities while reacting to both its external and internal environments. The systems approach uses feedback as a major technique to adjusting previous goals and objectives within an ever-changing environment. The systems management style uses an objective data base for analysis to compliment intuitional and subjective judgment. It is important to recognize the integrated nature of specific systems and to allow the manager to recognize the nature of problems and operations within the environment.

The systems concept is the recognition that any organization in a system is made up of segments, each of which has its own goals. Management recognizes that to achieve the overall goals of the organization, the entire system must be considered. Managers must seek to understand, quantify and measure the interrelationships and integrate them in a manner which allows the organization to pursue its total goals and objectives. Sometimes, a particular functional unit will have to choose a course of action which is not in its own best interest, because it is recognized that in some cases what is not good for a segment is efficient or beneficial for the whole.

The systems concept necessitates the use of objective analysis of decision problems because the concept has a substantial impact on both the planning and the executive function of management. The overall effectiveness of the organization is the main objective.

The systems approach also allows - encourages - the dissection of a function or problem or organism into subsystems - essentially elements. By so doing, attention is focused on aspects of the situation (or entity) that might have remained obscured. Such illumination causes better solutions and/or evaluations.

Systems management deals primarily with executing decisions within the constraints of the system's specifications and of redefining decisions for application of systems analysis. Systems management is specifically concerned with directing, motivating and controlling. It includes coordination and integration necessary to pull together various subsystems to ensure overall goal achievement.

The systems view conceives of any system as a complex of

"To whom correspondence should be addressed. 
interacting and interdependent parts. One important concept is that a chain of effects is produced by some action on some element of the system. These chains of effects should be taken into account in systems design, planning and decision making.

Project management is an integrator role. It blends the actions of many diverse groups into a systematic whole. This is why it is the organizational structure of the systems management approach; it creates synergism. In this sense, the project manager is truly a 'general systems manager' but with a limited objective. In fact, the limited objective is the main characteristic distinguishing project management from systems management. Project objectives are relatively short-term in nature, while system objectives cover the lifetime of the system, even though they may eventually undergo continual change.

The elements of project management require that constraints be recognized and incorporate a multi-step process touching on the following elements:

(a) Clear definition of goal or objective;

(b) recognition of environmental factors that act as constraints to that objective;

(c) analysis of requirements to arrive at the objective;

(d) establishment of alternative resources available to satisfy the requirements;

(e) definition of decision constraints used in evaluating the alternatives;

(f) study of trade-offs of alternative choices against the decision constraints;

(g) action;

(h) feedback of results against the original objective;

(i) adjustment of the system if the desired objectives are not being satisfied.

The systems approach has been defined as 'a logical and disciplined process of problem solving'. This process can be applied at various levels of management hierarchy. At the highest level, systems management comes into play, while at the lowest level, project management is used.

Systems management addresses the problems of an organization looking at the 'total picture' versus examination of the individual component. System management attempts to optimize the organization's resources. This would include such tactics as the assignment of the best personnel to the highest priority tasks, and the lower quality personnel to lower priority tasks. This thought process is centred on the long-term goals and objectives of a continuing entity.

Some people consider the systems approach to management as little more than the application of common sense, merely requiring that the total problem be identified and attacked in a systematic manner. The solution may lie in implementing a project management structure. The project manager can use the systems approach to solve problems within the confines of the project definition. Together these approaches to problem-solving provide a manager with the capacity to minimize threats and maximize opportunities for the organization.

Project management deals with organizing and controlling all activities involved in achieving a specific objective. Accomplishment of this objective is the project manager's only concern. The project manager is 'super-imposed' upon the functional organization. $\mathrm{He}$ /she does not attempt to interface the corporate goals with the project unless they coincide. $\mathrm{He} / \mathrm{she}$ normally controls no resources and has limited, if not nonexisting, authority.

A brief comparison of the two reveals great similarities with the major differences being the time duration of the task, the level within the hierarchy, the process and the use of the process. The 'meat' of the comparison is the process. Systems management involves studying the environment, formulating objectives to satisfy the needs or solve the problems of the organization, and then performing the tasks that will accomplish the objectives. Project management is a tool used to perform the given task. It involves the organizing and controlling of all activities involved in the achievement of a certain objective or task.

All companies should utilize systems management, yet not all companies should use project management. When the task to be accomplished is complex and the environment is dynamic, then project management should be used. Industries such as defence, construction and high-technology engineering are such examples. Companies that perform simple tasks, whether in a static or dynamic environment, may not need to use project management.

Both systems management and project management act in a limited and restricted way. 'Real' systems management and project management are more involved, more complex, and more comprehensive than relatively simple illustrations. They require both a theoretical and a practical understanding. They require continuing mental and physical effort to stay abreast of changes in the field. They are related concepts and practices which offer a promise of increased organizational effectiveness and improved individual and group productivity.

\section{Comparison}

Most business firms today are still structured along the same functional lines that date back to the turn of the century. Unfortunately, this classic organizational structure is no longer adequate in today's environment. The world is experiencing change in almost every area. Technology is expanding at a rapid rate. The market place is more competitive than ever. Government is everywhere with its expanding regulation. All of this creates an environment which makes it very difficult to efficiently and effectively control the resources in a typical business firm.

What is needed is an organizational structure designed to cope with the environment of today and the future. Fortunately, the ingredients exists to meet this challenge. The combination of the concepts of systems management and project management will enable a business firm to cope.

Systems management is generally considered an older concept than project management. The following are some highlights in the history of systems management:

1951 - Ludwig von Bertalanffy, a biologist, described 'open systems.' He identified how specialists in each subsystem could be integrated so as to get a better understanding of the inter-relationships.'

1956 - Kenneth Boulding identified the communication problems that can occur during systems integration. ${ }^{2}$

1960's - Johnson, Kast, and Rosenzweig wrote The Theory and Management of Systems which compared a business organization to a human body as follows: ${ }^{3}$

- Skeletal system,

- Muscle system - operating line elements,

- Circulatory system - necessary staff functions,

- Nervous system - the communication system,

- Brain - senior management.

1960's - Franklin Moore stated that the flow of resources is the basic force which identified the dynamic nature of the system. ${ }^{4}$ 
When systems theory is applied to business, the result is a management technique which can cut across the many functional lines - such as finance, manufacturing, engineering, and marketing - and still carry out the functions of management.

The following are some of the many definitions of the systems approach:

(a) A whole that cannot be taken apart without loss of its essential characteristics.

(b) An amalgamation of all the parts of science into an integrated whole.

(c) Not a science - but, is science taken as a whole and applied to the study of wholes.

(d) Denies the value of the separation of science and the humanities (views these as two sides of the same coin).

(e) Uses open systems planning.

(f) Is flexible.

(g) Encourages 'what if'.

(h) Starts with 'what is' and asks 'what would I like things to be'.

(i) Forces the examination of:

(i) Constraints;

(ii) driving forces;

(iii) risk and uncertainty.

Project management is relatively modern. While it existed twenty years ago, its application was very narrow because of the lack of computer technology for control functions. Basically, it was largely confined to the United States Department of Defence and contractors and construction companies. Since those days, the concept has been slowly spreading into almost all industries. The following are a few highlights in the history of project management:

1963 - The organization chart for TRW showed, in addition to the usual functional organization, a programme organization consisting of two programme offices. The two programme managers reported directly to the president of the company. ${ }^{5}$

1967 - W.C. Goggin, Board Chairman and Chief Executive Officer of Dow Corning, recognized signs of difficulty in his organization and began a series of changes which led to a multi-dimensional project management organizational structure. ${ }^{6}$

1967 - C.J. Middleton conducted a survey of corporations to establish the advantages and disadvantages of project management and how to set up an organization using project management. ${ }^{7}$

The following are some of the many definitions of project management:

(a) The directing and controlling of a relatively short term project or systems oriented organization with functional personnel assigned as required for the completion of specific goals.

(b) Based on 'two-handed' control in which the task responsibility is the project manager's but the administrative responsibility belongs to the functional manager.

(c) A collection of tools and techniques by which activities can be integrated throughout an organization - regardless of the organizational size or project complexity.

(d) A temporary management system which can respond rapidly to an everchanging situation.

(e) The planning, scheduling, directing, and controlling of company resources for a relatively short term project which has been established for the completion of specific goals and objectives.
Project management is not without its faults. One of the causes of problems in a business firm that uses project management is the difference in the success criteria used by functional managers and by project managers. A production manager, for example, is concerned with producing the product at minimum cost and maximum efficiency (timing is less important than the actual cost). An engineering manager is concerned with scheduling his complete set of activities while keeping his people working efficiently. Most functional managers have a consistent approach to any task. This is known as their 'management style'.

To a project manager, the success of a project is the criterion against which he will be measured. His management style is dictated by the project life cycle and is different from that of the functional manager. For example, in the planning stages he must exhibit a supportive or cooperative style. Later, in the production stage, he must be more directive if he is to meet specific time-cost constraints. During project phase-out, he should revert to a supportive style.

A project manager must be a generalist. He can be compared to an independent entrepreneur. He has to:

(a) Plan what to do and when to do it.

(b) Recruit his own team.

(c) Prepare a quotation on the job.

(d) Design the product.

(e) Make it.

(f) Deliver it.

(g) Dissolve his organization.

During projects, conflicts develop at the project/functional interface because the boundary between the roles of the project manager and the functional manager is not always clearly defined. The following define the relationship. ${ }^{8}$

(a) Project Manager:

(i) What is to be done?

(ii) When will the task be done?

(iii) Why will the task be done?

(iv) How much money is available to do the task?

(v) How well has the total project been done?

(b) Functional Manager:

(i) Who will do the task?

(ii) Where will the task be done?

(iii) How will the task be done?

(iv) How well has the functional input been integrated into the project?

\section{Similarities and differences}

By now the reader is probably thoroughly confused concerning the similarities and differences between project and systems management. Ten years ago, project management was considered as a major 'subset' of systems management, whereas today the situation appears to be reversed. Yet, regardless of which way one looks at these two approaches, there are definite similarities:

- Both consider the impact of the external and internal organization.

- Both require organizational flexibility.

- Both require performance measurement techniques.

- Both recognize life cycle influences.

- Both require the use of management principles and functions.

- Both recognize the need for systems modelling.

- Both are responsive to rapidly changing environments.

- Both require the need for a 'team approach' to problemsolving, planning and execution. 
- Both try to harmonize conflicting objectives.

- Both try to achieve overall (system/project) effectiveness.

- Both may sacrifice other goals to obtain real goals.

- Both utilize information systems.

- Both integrate several functional components.

- Both set goals, allocate resources and control performance.

- Both have control and feedback mechanisms.

- Both have input, processing, and output.

- Both promote good working relationships between personnel.

- Both require authority, responsibility and accountability.

- Both have integrated planning and control systems.

- Both stress flexibility.

- Both solve problems by looking at the total picture rather than 'individual' components.

- Both integrate and unify scientific information across several fields of knowledge.

- Both encourage active cooperation from employees.

- Both keep people informed and satisfied by aligning motives with objectives (personal and corporate).

- Both help people to develop.

- Both help people to solve personal and professional problems.

The above list of similarities is impressive if we look at the macro levels of project and systems management. On the micro level, however, there are major differences. For example, on the macro level, both projects and systems tend to have welldefined goals and objectives. On the micro-level, systems goals are aligned to the total company whereas project goals and objectives are unique to the project, thus creating conflict. The following list identifies other major differences at the micro level of observation:

- Project management is normally of a finite time duration whereas systems are more ongoing. Projects die whereas systems continue.

- Systems have direct control over all resources whereas projects must share resources, often through conflict, prioritization and negotiation.

- Systems managers have direct control over employee performance measurement and salary/merit increases whereas project managers have an indirect input at best.

- Systems managers have direct control over system staff whereas projects are staffed by line personnel.

- Systems are designed to perform repetitive tasks whereas projects accomplish unique or one-of-a-kind tasks not easily handled by the traditional structure.

- Systems generally function vertically whereas projects function horizontally (i.e., multidirectionally).

- Project managers have limited power and authority as compared to system managers.

- The shifting of personnel in a project environment may disrupt the organization more than in a system.

- Systems interface well with strategic planning functions whereas projects interface with operational functions.

- Systems seek long-term talent and resources whereas projects seek short-term talent.

- Project management is not conducive to the development of clear job descriptions whereas systems management job descriptions are precise.

- Systems allow for better training of new employees than do projects.

- Projects create more conflict at the functional interface positions than do systems.

- Systems are conservative in nature whereas projects en- courage risk-taking.

- Systems promote the scalar principle where the chain of authority is from the superior to the subordinate through the organization. Although projects do have a vertical chain of command, the prime emphasis is on horizontal and diagonal work flow.

- Systems management advocates that line functions have direct responsibility for accomplishing the objectives whereas in project management line functions are in a support position.

- Systems management advocates that important business is conducted through a pyramidal structure of superiors and subordinates whereas project management uses a peerto-peer, manager-to-expert, and associate-to-associate relationship to conduct much of the salient business.

- Project objectives are multilateral because management of the project is a joint venture of many relatively independent organizations. Systems objectives are unilateral and are sought by the parent unit working within the environment.

- Systems management advocates that the superiorsubordinate relationship is maintained through the functional authority and advisory staff services. Project managers have large responsibilities but virtually no authority.

- The systems manager's authority comes from his relative position in the hierarchy whereas the project manager's authority (and his power) comes from his technical and managerial expertise, credibility with employees and ability as a sound decision-maker.

- Project organizational forms are less rigid and thrive on flexibility in adapting to an ever-changing environment whereas systems may be inflexible.

- The life cycle phases of a system overlap whereas life cycle phases of a project are normally well-defined and do not overlap.

- Systems employ the five management functions of planning, organizing, staffing, controlling and directing whereas project management does not include the staffing function.

- Conflicts and their resolution have a higher frequency and intensity in project management.

- Systems management may have more complex information systems but project management information systems have a greater frequency of use.

- The feedback of information/status reporting is more critical in projects than systems.

- Systems managers have more control over input, processing and output activities than do project managers.

- Projects may cut across more of the organization than do systems.

- Systems managers generally have more time and more of an interest when it comes to helping employees solve personal and professional problems.

- Executives get more actively involved in projects than in systems.

\section{Summary}

While these differences may be more theoretical than actual, they do exist and can affect either manager's mode of operation and philosophy. The comparison highlights two singular characteristics:

(a) Projects are managed through extensive participation of organizations and people not under the direct control of the project manager. 
(b) Systems managers may operate as traditional line managers with formally defined position, power and authority.

Whether systems management is an outgrowth of project management or vice-versa, there will continue to be a controversy whose solution rests in the eyes of the beholder. On the macro level, project management operates in much the same way as systems management does, and probably as a pure system rather than as traditional management.

As the complexity of tasks increase and environments become more dynamic, the growth of project management can expect to increase at a faster rate than systems management. Tasks which cannot be readily handled by the traditional structure or systems management will be placed under the auspices of project management. From an authority point of view, systems can be effective only at those points where formal authority exist. Now, project management can be defined as the systems approach to management for those activities that do not fall under the normal or routine functions of an organization.

\section{Notes and References}

I. See Bertalanffy, L. Von. 1972. General systems theory; foundations, development, applications. New York: G. Braziller, for source information.

2. Boulding, K.E. April, 1956. General Systems Theory: The Skeleton of Science, Manage. Sci., vol. 2, no. 3, p. 197.

3. Johnson, R.A., Kast F.E. \& Rosenzweig, J.A. 1967. The theory and management of systems. 2nd edition. New York: McGraw-Hill.

4. Moore, F.G., (ed.), 1964. A management sourcebook. New York: Harper \& Row, p. 104.

5. TRW Systems Group tried to make almost an instantaneous conversion from a traditional to a matrix organizational form. Managing the conversion was accomplished through T-groups and special study sessions. The TRW Systems Group Studies can be found in cases 9-476-117, 9-413-066 and 9-413-069 distributed by the Intercollegiate Case Clearing House.

6. Goggin, W.C.. January-February 1974. How the multidimensional structure works at Dow Corning, Harv. Bus. Rev. p.54.

7. Middleton, C.J. March-April 1967. How to set up a project organization. Harv. Bus. Rev. vol. 45, p.73.

8. Cleland, D.1., \& King, W.R., 1968, 1975. Systems analysis and project management. New York: McGraw-Hill. 